\title{
Statistical Analysis of Crop Production Risks of Households in Jimma Rare District, Horro Guduru Wollega Zone, Ethiopia
}

\author{
Getachew Tadesse $^{1^{*}} \quad$ Adem Kedir $^{2} \quad$ Bosena Tegegne ${ }^{3}$ \\ 1. Department of Statistics, Ambo University, P.O. Box 19, Ambo, Ethiopia \\ 2. Department of Agricultural Economics, Arsi University, P.O. Box 193, Arsi, Ethiopia \\ 3. School of Agricultural Economics and Agribusiness, Haramaya University, P.O. Box 138, Dire Dawa, \\ Ethiopia
}

\begin{abstract}
Background: This study aims at assessing the factors influencing households' crop production risks due to hail or heavy rainfall in Jimma Rare District. Methods: The data was generated from primary source and 196 households were selected from Jimma Rare District using Multistage sampling techniques. Both descriptive statistics and econometric model (Poisson or Negative Binomial regression) were applied in this study to analyze the data collected from the selected sample households. Results: The survey result shows that, the average number of crop production risks due to hail or heavy rainfall was 1.62 with variance equal to 2.04 . The result of Negative binomial regression model shows that, age of household heads and total land size have positively and significantly influenced the number of crop production risks due to hail or heavy rainfall faced by households, but negatively affected by livestock size, access to extension service, and access to training. Conclusion: This study revealed that rural households are affected by different demographic and socio-economic factors, farm characteristics, institutional factors, and environmental factors. Specifically, the finding revealed that, an increase in age of household heads and total land size increases number of crop production risks faced by farmers due to hail or heavy rainfall in the area whereas an increase in livestock size, access to extension service, and access to training decreases the number of crop production risks due to hail or heavy rainfall by farmers in the study area. Therefore, the study recommends that, improving access to training, availability of agricultural inputs at planting time, and preparing experience sharing among farmers should be promoted to decrease number of crop production risks due to hail or heavy rainfall and increase the productivity of farmers by appropriate decision of crop production in the study area.
\end{abstract}

Keywords: Households, Crop Production Risks, Jimma Rare, Poisson regression, Negative binomial regression, Oromiya, Ethiopia

DOI: $10.7176 / \mathrm{JBAH} / 10-10-04$

Publication date:May $31^{\text {st }} 2020$

\section{Backgrounds}

Agriculture production is often characterized by high variability of production outcomes, that is, by production risks. Production risks derives from the uncertain natural growth processes of crops and livestock which affect both the quantity and quality of commodities produced. Households cannot predict with certainty the amount of output their production process will yield due to external factors such as weather conditions, pests and diseases (ARD, 2005).

Crop production risks will cause households to be less willing to undertake activities and crop production decision that have higher expected outcomes since it depends up on the uncontrollable environmental factors (Nigist, 2007). Production risks are generally an unavoidable part and managing these risks is an important aspect of protecting livelihoods and opening up opportunities to enhance productivity and income growth.

Ethiopian agriculture is heavily dependent on natural rainfall. The amount of rainfall and other climatic factors during the growing season are critical to crop yields and food security problems. Ethiopia has a variety of grain crops growing in different agro-ecological zones which are produced as a source of income and food by smallholder farmers in different regions. The production of crops varies across regions depending on the size and agro-ecological difference. For example, the highest proportion of crop production and rearing of livestock production is from Oromiya Region because of relatively abundant rainfall, suitable soils and other agricultural potentialities (CSA, 2012).

The objectives of the study is to identify major factors affecting households' crop production risks due to hail or heavy rainfall in the study area

\section{Methods}

Study Area: The study was carried out in Jimma Rare Woreda which is one of the districts in Horro Guduru Wollega Zone of Oromiya Regional State in Ethiopia. The district is bounded on the west by Jimma Horro, on the north by Guduru, on the east and south by the Guder River which separates it from the West Shewa Zone. The administrative center of the district is Wayu; other towns in Jimma Rare include Goben (JRWOA, 2014). It is 
located at $245 \mathrm{~km}$ from the capital city of the country, Addis Ababa. A survey of the land in this district shows that $73.8 \%$ is cultivable or arable, $16 \%$ is grassland, $4.6 \%$ is forest, and the remaining $5.6 \%$ is considered swampy, mountainous or otherwise unusable (CSA, 2007). The district is classified as mid- altitude which is about $78 \%$ of the area, and the rest $22 \%$ is high altitude agro ecological zones. The annual rainfall ranges $900-1400 \mathrm{~mm}$ per year with annual temperature ranging from $18-25^{\circ} \mathrm{C}$ during the year. The total population for this district was 71552 people of whom $35244(49.26 \%)$ are men and the remaining are women. Out of 71552 total populations in the study area, 7710 are household heads that live in rural areas and $86.25 \%$ are men headed households and the remaining are women headed. The primary source of income is crop production. The secondary source of livelihood for the rural people in the area is livestock production. (JRWOA, 2014).

\section{Data Types, Source and Method of Data Collection}

Both primary and secondary sources of data were used in this study. The primary data (both qualitative and quantitative) were collected (in January to February 2015) for the study includes the socio-economic characteristics of the households, farm characteristics, and crop production choices of households. Secondary data was collected by reviewing documents of the administration office such as list of kebeles and number of households in each kebele in Jimma Rare district. A semi-structured questionnaire was developed for the collection of necessary primary information. This questionnaire was prepared in English and translated into local language (Afan Oromo) to make the communication easier during the primary data collection from the households. In order to select a representative sample of farm households, two- stage sampling techniques were employed. In the first stage, four kebeles were selected using simple random sampling techniques (lottery method) from 18 kebeles. In the second stage, sample of households were drawn from the selected kebeles for the interview based on simple random sampling.

In the determination of sample size where there is large population, but we do not know the variability in the proportion about the households' crop production risk due to hail or heavy rainfall , $\mathrm{p}=0.5$ is considered as suggested by Kothari (2004). To determine the required sample size out of $7710,95 \%$ confidence level, and $7 \%$ acceptable error rate during sampling were used. Based on this information, the sample size was determined by using the statistical formula given below:

$$
n=\frac{n_{o}}{1+\frac{n_{o}}{N}}
$$

Where $n_{o}=\frac{\left(Z_{\alpha / 2}\right)^{2} \times p \times q}{\varepsilon^{2}}=\frac{(1.96)^{2} \times 0.5 \times 0.5}{(0.07)^{2}}=196$

$n_{o}=$ the initial sample size, $\mathrm{p}$ is the estimated proportion of households whose crop production affected due to hail or heavy rainfall, $q=1-p$, and $Z_{\alpha / 2}$ is the value of standard normal distribution for a given level of significance. The sample size from each kebele is determined as:

$$
n_{h}=\frac{N_{h} \times n}{N}
$$

Where, $\mathrm{N}$ - is the total number of households in all selected sample kebeles, $\mathrm{N}_{\mathrm{h}}$ - is the number of households in $\mathrm{h}^{\text {th }}$ strata (kebele), and $n_{h}$ - is the sample size selected from $\mathrm{h}^{\text {th }}$ strata.

Table 1: Sampling frame of the selected kebeles

\begin{tabular}{lcc}
\hline Kebeles & No of households & Sample size \\
\hline BeddaWorke & 630 & 79 \\
Ibsa Illamu & 338 & 42 \\
Gemada & 232 & 29 \\
Keku Qallo & 365 & 46 \\
\hline Total & 1565 & 196 \\
\hline
\end{tabular}

Source: Kebele administration office, 2015

\section{Method of Data Analysis}

Two types of data analysis were employed, namely descriptive statistics and inferential statistics (Econometric models). Descriptive statistics include mean, standard deviation, percentages and frequency, student's t-tests and chi square test were run using SPSS version 20 and STATA 11 software packages were used to describe, compare, and contrast the data with respect to the desired characteristics. Inferential statistics (Econometric model) such as Poisson or Negative binomial model was used to identify factors influencing crop production risks due to hail or 
heavy rainfall of households.

Negative Binomial Regression Model

The Negative Binomial regression model is a direct extension to the Poisson model that allows for overdispersion. It is characterized by two parameters $\lambda$ and $\alpha$, where $\alpha$ is typically termed the negative binomial dispersion parameter. The probability mass function for the negative binomial distribution with parameters $(\lambda, \alpha)$ for a random variable $Y_{i}$ is given by:

$$
P\left(y_{i}\right)=\frac{\Gamma\left(y_{i}+1 / \alpha\right)}{y_{i} ! \Gamma(1 / \alpha)}\left(\frac{1}{1+\alpha e^{X_{i}^{\prime} \beta}}\right)^{1 / \alpha}\left(\frac{\alpha e^{X_{i}^{\prime} \beta}}{1+\alpha e^{X_{i}^{\prime} \beta}}\right)^{y_{i}}, i=1,2, \ldots, n
$$

with mean $E\left(y_{i} / x_{i}\right)=\lambda_{i}=e^{X_{i}^{\prime} \beta}$ and variance $\operatorname{Var}\left(y_{i} / x_{i}\right)=\lambda_{i}\left(1+\alpha \lambda_{i}\right)$. Where, $\alpha$ is the dispersion parameter and characterizes the degree of over-dispersion in count data and $\Gamma($.$) is a gamma function.$

The likelihood function of negative binomial model is given by:

$$
L(\alpha, \beta)=\prod_{i=1}^{n} \frac{\Gamma\left(y_{i}+1 / \alpha\right)}{y_{i} ! \Gamma(1 / \alpha)}\left(\frac{1}{1+\alpha e^{X_{i}^{\prime} \beta}}\right)^{1 / \alpha}\left(\frac{\alpha e^{X_{i}^{\prime} \beta}}{1+\alpha e^{X_{i}^{\prime} \beta}}\right)^{y_{i}}
$$

and the log-likelihood function is

$$
\operatorname{Ln} L(\alpha, \beta)=\sum_{i=1}^{n}\left(y_{i} \ln \alpha+y_{i}\left(x_{i}^{\prime} \beta\right)-\left(y_{i}+\frac{1}{\alpha}\right) \ln \left(1+\alpha e^{X_{i}^{\prime} \beta}\right)+\ln \Gamma\left(y_{i}+\frac{1}{\alpha}\right)-\ln y_{i} !-\ln \Gamma\left(\frac{1}{\alpha}\right)\right)
$$

5

As for the Poisson model, the estimation of the model parameters can be done by differentiating the log likelihood function with respect to the parameters $\alpha$ and $\beta$.

Over-dispersion: Under negative binomial regression model, if the estimated alpha coefficient is zero, then the conditional mean is equal to the conditional variance $\left(E\left(y_{i} / x_{i}\right)=\operatorname{Var}\left(y_{i} / x_{i}\right)\right)$ and the Negative binomial model reduces to the Poisson model. If the estimated alpha coefficient is significantly greater than zero, then the conditional variance exceed the conditional mean $\left(\operatorname{Var}\left(y_{i} / x_{i}\right)>E\left(y_{i} / x_{i}\right)\right)$ and over-dispersion is present in the data. Under such circumstance, the Poisson model is inappropriate and Negative binomial regression model is preferred.

\section{Testing for Over-dispersion}

If over-dispersion is present, then estimates are inefficient and standard errors are biased downward. It is therefore important to test for overdispersion. There are various ways to do this:

1. $\mathrm{H}_{0}: \alpha=0$ against $\mathrm{H}_{1}: \alpha>0$ (The test is one-tailed, because $\alpha$ cannot be less than zero.)

This is to test for the significance of the over-dispersion parameter $(\alpha)$. The presence of the over-dispersion parameter alpha in the negative binomial regression model is justified when the null hypothesis is rejected. For a general Negative binomial model, the likelihood ratio test for alpha is given by:

$$
L R T_{\alpha}=-2(l(\hat{\lambda})-l(\hat{\lambda}, \hat{\alpha}))
$$

Where, $l(\hat{\lambda})$ and $l(\hat{\lambda}, \hat{\alpha})$ are respectively, the maximized log-likelihood under the Poisson regression and negative binomial regression models. Likelihood ratio test is compared with the probability mass of one half at zero and one half chi-square distribution with one degree of freedom.

2. Wald test of $\ln ($ alpha $)=1$ (which corresponds to a test of alpha $=0$ ): Using the asymptotic normal Wald type " $t$ " statistic defined as the ratio of the estimate of $\alpha$ to its standard error. In other words, the Wald test statistic has the form $\left[\frac{\ln (\text { alpha })-1}{S E(\ln a l p h a)}\right]^{2}$ which follows chi-square distribution with one degree of freedom.

\section{Results and Discussion}

Descriptive Statistics: Descriptive statistics such as mean, standard deviation, and percentage were used to describe the major factors that explain household's crop production risks due to heavy rainfall or hail. 
Table 2: Demographic and resource holding by sample households (Continuous variables)

\begin{tabular}{llccc}
\hline Variables & Min & Max & Mean & Std. Dev \\
\hline Age of households (Year) & 24 & 66 & 42.77 & 9.037 \\
Total land size (hectare ) & 0 & 7.00 & 2.96 & 1.46 \\
Livestock size (TLU) & 1.44 & 19.25 & 8.04 & 4.42 \\
\hline
\end{tabular}

Source: Computed from own survey data, 2015

The survey results showed that the average age of the sample households was 42.77 years with standard deviation of 9.04 and the age of sample households range between 24 and 66 years. The average suggests that farmers are within the productive age group. According to land holding of the households the average total land holding of the sample households was 2.96 hectare with standard deviation of 1.46 and ranges from zero to seven hectare. This shows that the households with large land size have a chance to get access to agricultural extension services and new agricultural inputs. Similarly, the average tropical livestock holding of sample household was 8.04TLU with standard deviation of 4.42 and range from 1.44 to 19.25 TLU (Table 2).

Table 3: Access to and Utilization of services

\begin{tabular}{llcl}
\hline Variables & Category & Number of observation & Percent \\
\hline Extension services & Not access & 18 & 9.2 \\
& Access & 178 & 90.8 \\
Access to training & Not participated & 61 & 31.1 \\
& Participated & 135 & 68.9 \\
\hline
\end{tabular}

Source: Computed from own survey, 2015

The survey result shows that, $135(68.9 \%)$ of the respondents had access to training about the use of fertilizers, compost and chemicals but not on the production decisions of different crops and how to escape from crop production risks that faced by the households and $61(31.1 \%)$ had no access to training. Similarly, according to access to agricultural extension services, $178(90.8 \%)$ of the respondents had access to agricultural extension services and $18(9.2 \%)$ of the respondents were not participated to access to agricultural extension services (Table 3).

Table 4: Number of production risks faced by households due to hail or heavy rainfall

\begin{tabular}{lccc}
\hline № & Frequency & Percent & Cum. Percent \\
\hline 0 & 49 & 25.0 & 25.0 \\
1 & 54 & 27.6 & 52.6 \\
2 & 47 & 24.0 & 76.5 \\
3 & 27 & 13.8 & 90.3 \\
4 & 12 & 6.1 & 96.4 \\
5 & 4 & 2.0 & 98.5 \\
6 & 1 & 0.5 & 99.0 \\
7 & 2 & 1.0 & 100.0 \\
\hline Total & & \multicolumn{2}{c}{100.0} \\
\hline
\end{tabular}

Source: Computed from own survey, 2015

The pattern and amount of rainfall directly affect yields and the level of production of crops. The survey result shows that, the average number of production risks due to hail or heavy rainfall was 1.62 with variance equal to 2.04 (Table 4).

Econometrics Model: This section deals with inferential statistics of Negative binomial regression for count data on households' crop production risk due to hail or heavy rainfall in the study area. Negative binomial regression model were estimated to analyze factors influencing crop production risks due to hail or heavy rainfall faced by the sample households. The estimated Poisson model was tested below for overdispersion since the model has been criticized because of its implicit assumption that the variance of the dependent variable equals its mean

Over-dispersion Test: The adequacy of the Negative binomial model could be tested by likelihood ratio test. The null hypothesis is that the estimated dispersion parameter is equal to zero. The likelihood ratio test of alpha as indicated by chi-square $(17.8)$ is statistically significant $(p=0.0033)$, suggesting that alpha is significantly different from zero (Table 5). One can conclude that there is over-dispersion problem in the data which leads the conditional variance of the number of production risks greater than its conditional mean. Thus, the Poisson model was rejected, and therefore a Negative binomial model was preferred since it allows for over-dispersion (Cameron and Trivedi, 2005).

Goodness of Fit Tests: The overall goodness of fit for negative binomial regression model was tested using loglikelihood ratio test. The likelihood ratio test is calculated as twice the difference between the log-likelihood with all predictors in the model and the log-likelihood without any predictor in the model (the intercept only model). This test is distributed as chi-squares with five degrees of freedom. The log likelihood as indicated by chi-square statistic $(17.72)$ is highly statistically significant $(\mathrm{p}=0.0000)$ at $1 \%$ level of significance, suggesting that all the 
estimated coefficients except the constant are equal to zero was rejected (Table 5). One can conclude that the full model statistically significantly predicts the response variable better than the constant only model. This is indicating that the existence of a relationship between the combination of explanatory variables and the response variable was supported.

Table 5: Estimated parameters of NB regression model for production risks

Negative binomial regression

Number of obs $=196$

Dispersion $=$ mean

LR chi2(5) = 17.72

Log likelihood $=-314.87833$

Prob $>$ chi2 $=0.0000$

Pseudo R2 $=0.0274$

\begin{tabular}{lllllll}
\hline HailorHRain & Coef. & Std. Err. & $\mathrm{z}$ & $\mathrm{P}>\mathrm{z}$ & \multicolumn{2}{c}{ [95\% Conf. Interval] } \\
\hline AGE & .0160196 & .0081098 & 1.98 & 0.048 & .0001247 & .0319144 \\
TLND & .1102291 & .0497389 & 2.22 & 0.027 & .0127428 & .2077155 \\
TLU & -.0344245 & .0148514 & -2.32 & 0.020 & -.0053163 & .0635327 \\
AEXT & -.5529186 & .2539144 & -2.18 & 0.029 & -.0552555 & 1.050582 \\
TRAIN & -.3555321 & .1449788 & -2.45 & 0.014 & -.6396853 & -.0713789 \\
cons & .2718867 & .376749 & 0.72 & 0.471 & -.4665278 & 1.010301 \\
\hline /nalpha & -1.617023 & 0.561744 & & & -2.718020 & -0.516025 \\
alpha & 0.480587 & 0.405711 & & & 0.091873 & 2.513950 \\
\hline
\end{tabular}

Likelihood-ratio test of alpha $=0$ : $\operatorname{chibar2}(01)=17.8$, Prob $>=\operatorname{chibar} 2=0.0033$

Discussions for significant Variables

Age of Households Head (AGE): Age of the household heads positively and significantly influenced production risks due to hail or heavy rainfall and the result is contradictory with the expected hypothesis. The survey result shows that, holding all other variables in the model constant, an increase in age of household heads by one year increases the log expected number of production risks due to hail or heavy rainfall by 0.016 (Table 5). The possible reason is that, older household heads have less labor to manage production risks and are rigid to accept modern agricultural technologies than younger household heads.

Total Land Size (TLNDS): Total land size of households positively and significantly affected the number of production risks due to hail or heavy rainfall faced by households. The sign of the parameter estimate is contradictory with the hypothesized one. The survey result shows that, an increase in total land size of households by one unit increases the log expected number of production risks due to hail or heavy rainfall by 0.110 , keeping all other variables in the model constant (Table 5). The implication is that households with large land size are affected by uncontrollable factors such as low level of crop management practices, weeds, pest and diseases, floods (heavy rainfall), and post-harvest crop losses compared to households with less or small total land size.

Livestock Size (TLU): Livestock size in terms of tropical livestock unit negatively and significantly influenced the number of production risks due to hail or heavy rainfall faced by the households. The sign of the parameter estimate confirms with the expected hypothesis. The survey result shows that, an increase in livestock size by one TLU decreases the log expected number of production risks due to hail or heavy rainfall by 0.034 , holding all other variables constant (Table 5). The farmers with large livestock size have better chance to manage production risks by selling their livestock and could invest on stable crop production to reduce their crop failures.

Access to Extension Service (AEXT): Extension agents give advice to farmers on better farming practices. However, not all households often have access to these services. The survey reveals that extension service negatively and significantly influenced the number of production risks due to hail or heavy rainfall. Holding all other variables in the model constant, households with access to extension decreases the log expected number of production risks by 0.553 relative to those without access (Table 5). The implication is that household's access to extension service increases the ability of households' to acquire important information as well as other related agricultural technology which in turn increases households ability to reduce production risks due to hail or heavy rainfall in the study area.

Access to Training (TRAIN): Access to agricultural training is an important step in increasing the knowledge and experience of farmers to reduce their production risks. The survey reveals that, access to training negatively and significantly influenced the number of production risks. The farmers with access to training decreases the log expected number of production risks by 0.356 compared to those without access to training, holding all other variables constant (Table 5). The possible explanation is that participated households in agricultural training most likely increase the likelihood of reducing the production risks due to hail or heavy rainfall causes of floods. The probable reason is that agricultural training given by extension workers to households enhances agricultural crop production skills, knowledge and experience of row planting crops and planting trees. This situation helps households to get better crop production and this leads to reduce crop production risks of households.

\section{Limitation of the study}

The study would not include sources of other risks like market risk, human or personal risk, institutional risk and 
financial risk of households and it would not include production decisions to use livestock's. Furthermore, since Oromia has wide range of diverse agro-ecologies, institutional capacities, organizations and environmental conditions, the result of the study may have limitations to make generalizations and make them applicable to the country as a whole. However, it may be useful for areas with similar context with the study area.

Conclusions: Farmers are knowingly or unknowingly affected by different demographic and socio-economic factors, farm characteristics, institutional factors, and environmental factors. The empirical results of Negative binomial regression model showed age of household heads, total land size, livestock size, access to extension service, and access to training were significantly influenced crop production risks due to hail or heavy rainfall. Specifically, the finding revealed that, an increase in age of household heads and total land size increases number of crop production risks faced by farmers due to hail or heavy rainfall in the area whereas an increase in livestock size, access to extension service, and access to training decreases the number of crop production risks due to hail or heavy rainfall by farmers in the study area.

Recommendations: The recommendations or policy implications were drawn based on the significant variables from the analysis of present study.

The number of crop production risks due to hail or heavy rainfall was statistically influenced by the use of extension service and access to training. Agricultural extension services should be strengthened through training and upgrading the educational level of extension workers which increases the interaction between farmers and extension officers in the area. In addition to this, agricultural extension workers should prepare experience sharing forums among farmers on the choices of crop production and how to escape crop failure due to risk factors.

Empirical results showed that total land size is significant for both crop production risks due to hail or heavy rainfall and crop production choices. Land is an important resource for farmers. Therefore, the concerned body should be able to increase the awareness of farmers on the proper application on land use and how to manage land to give high agricultural production and productivity for farmers.

\section{Declarations}

Ethics and consent to participate

Ethical approval was obtained from Haramaya University, college of computing and Informatics.

Consent for publication

Not applicable

\section{Availability of data and materials}

The datasets in which conclusion has taken is available on request.

Competing interests

The authors declare that they have no competing interests.

Funding

Sponsored by Haramaya University

Acknowledgement

The Author completely thanks Dr. Adem Kedir and Dr. Bosena Tagegne for their precious time, professional suggestions, guidance, valuable and constructive comments, and intellectual encouragement for this research. Also, I express my gratitude to my colleagues and librarians of Haramaya University who assisted me in borrowing different reference books for the completion of the work and Haramaya University for offering opportunity and financial support.

\section{References}

Aemro Tazeze, Jemma Haji, and Mengistu Ketema. 2012. Climate Change Adaptation Strategies of Smallholder Farmers: The Case of Babilie District, East Harerghe Zone of Oromiya Regional State of Ethiopia. Journal of Economics and Sustainable Development, Vol.3, No.14, 2012

AfDB. 2011. Federal Democratic Republic of Ethiopia: Country Strategy Paper 2011-15

Aimin, H. 2010. Uncertainty, risk aversion and risk management in agriculture. Agriculture and Agricultural Science Procedia 1:152-156.

Andersen, T. A. 2008. The performance relationship of effective risk management: Exploring the firm-specific investment rationale. Long Range Planning, Vol. 41, pp. 155-176

Anton, J. and Kimura, Sh. 2009. Farm Level Analysis of Risk, and Risk Management Strategies and Policies: Evidence from German Crop Farms, International Association of Agricultural Economists Conference, Beijing, China, August 16-22, 2009

ARD. 2005. Managing Agricultural production risk. The World Bank Agriculture and Rural Development Department. Accessed on March 20, 2016

Cameron, A.C, and Trivedi, P.K. 2005. Micro econometrics, Methods and Applications

Campbell, T. 2008. Risk management: Implementing an effective system. Accountancy Ireland, vol. 40(6), pp.5466

Cochran, W. G. 1977. Sampling Techniques, John Wiley and Sons, Inc., Canada 
Crane, L. Gantz, G. Isaacs, S. Jose, D. and Sharp, R. 2013. Introduction to Risk Management, understanding agricultural risk second edition

CSA. 2007. Oromiya Likelihood Zone Reports, Jimma Rare Woreda, Horro Guduru Wollega Zone. Accessed on September 12, 2015

CSA. 2012. The Federal Democratic Republic of Ethiopia Central Statistical Agency, Household Consumption and Expenditure Survey 2010/11, Analytical Report, October 2012, Addis Ababa, Ethiopia

CSA. 2014. The Federal Democratic Republic of Ethiopia Central Statistical Agency Agricultural Sample Survey 2013 / 2014, Vol.I, Report on Area and Production of Major Crops, Addis Ababa, Ethiopia

Donye, A. O. and Ani, A. O. 2012. Risks and uncertainties in food production and their implications for extension work in Nigeria, Agriculture and Biology Journal of North America 3(9): 345-353

Greene, W. H. 2000. Econometric analysis, fourth edition, Prentice Hall, New Jersey

Greene, W. H. 2003. Econometric analysis, Fifth edition, Prentice Hall, New Jersey

Greene, W.2012. Econometric Analysis. 7th edition. NJ, Prentice Hall, Pearson.

Hansson, H. and Lagerkvist, C. J. 2012. Measuring farmers' preferences for risk: a domain-specific risk preference scale, Journal of Risk Research, Vol. 15 (7), pp.737-753

Hardaker, J.B., Huirne, R.B.M., Anderson, J.R. and Lien, G. (2004). Coping with Risk in Agriculture. 2 nd edition. Oxfordshire, UK. Accessed on March 2, 2016

Ito, T. and Kurosaki, T. 2009. Weather risk, wages in kind, and the off-farm labour supply of agricultural households in a developing country, American Journal of Agricultural Economics 91: 697-710

JRWOA. 2014. Reports on the agricultural production of farm household in Jimma Rare Woreda. Accessed on October 5, 2014

Kahan, D. 2008. Managing risk in farming, Farm management extension guide, Food and agriculture organizations of the United Nations Rome 2008

Kothari. C. R. 2004. Research Methodology Methods and Techniques, New Delhi, India, New Age international Publishers.

Kouame, E. and Komenan, A. 2012. Risk preferences and demand for insurance under-price uncertainty: an experimental approach for cocoa farmers in côte d'ivoire, research paper no.13

Kumilachew Alamerie, Mengistu Ketema, Fekadu Gelaw. 2014. Risks in Vegetables Production from the Perspective of Smallholder Farmers: The Case of Kombolcha Woreda, Oromiya Region, Ethiopia. Agriculture, Forestry and Fisheries. Vol. 3, No. 1, 2014, pp. 1-5.

Le, T. C. and Cheong, F. 2009. Measuring Risk Levels and Efficiency of Risk Management Strategies in Vietnamese Catfish Farming. International Journal of Social, Human Science and Engineering, Vol. 3 No: 9

Lwayo, M. K. 2012. Risk Preferences and Consumption Decisions in Organic Production: The Case of KwazuluNatal and Eastern Cape Provinces of South Africa, Agricultural Economics, University of Fort Hare, Alice South Africa.

Mahmud Y., Menale K., and Kohlin, G., 2009. Risk Implications of Farm Technology Adoption in the Ethiopian Highlands. Environment for Development, Discussion paper series, No.09-13.

Nigist Haile. 2007. An Economic Analysis of Farmers' Risk Attitudes and Farm Households' Responses to Rainfall Risk in Tigray Northern Ethiopia, Wageningen University

Nmadu, N., Eze, P., and Jirgi, J. 2012. Determinants of Risk Status of Small Scale Farmers in Niger State, Nigeria. British Journal of Economics, Management \& Trade 2(2): 92-108

Ridha B. M and Alnaji L. 2013. The Methods of Measurement and Analysis of Risks in Businesses: A Case Study on the Jordan Valley Authority, Developing Country Studies, Vol.3, No.2, 2013

Rosta, J. 2008. Risk management: Models built on good times fail in bad: Will going back to basics and empowering CROs fix the problem? (Front and center), American Banker, 118(12).

Salimonu, K. K. and Falusi, A. O. 2009. An Empirical Analysis of Attitude towards risk and the influence of socioeconomic and demographic factors among food crop farmers in Osun State, Nigeria. International Journal of Applied Agricultural and Apicultural Research, 5(1), 32-43.

Wooldridge, J. M., 2003. Introductory Econometrics: A Modern Approach. 2nd edition, Thomson South-Western, Mason, $\mathrm{OH}$.

Wulu, J.T., Jr., K.P. Singh, F. Famoye, T.N. Thomas and G. McGwin .2002. Regression Analysis of Count Data. Journal of Indian Social and Agricultural Statistics, 55(2) : 220 231

Zivanomoyo, J. and Mukarati, J. 2013. Determinants of Choice of Crop Variety as Climate Change Adaptation Option in Arid Regions of Zimbabwe, Russian Journal of Agricultural and Socio-Economic Sciences, 3(15) 